\title{
Total Quality Management Practices from Unit Nurse Managers' Perspectivese
}

\author{
Fouada Mohamed Shaban, Sanaa Moustafa Safan and Soha Mamdouh Elkholy* \\ Nursing Administration Department, Faculty of Nursing, Menoufia University, Egypt
}

Submission: July 25, 2018; Published: August 03, 2018

*Corresponding author: Soha Mamdouh Elkholy, Nursing Administration Department, Faculty of Nursing, Menoufia University, Egypt, Tel: 1062407475; Email: mamdouh.soha@yahoo.com

\begin{abstract}
Background: Unit nursing managers act as a quality model by personally exhibiting desired characteristics and spending time walking around, listening to staff members, learn to be more like a coach, provide autonomy and allow risk taking while being fair and compassionate, engage in the delicate balancing act of ensuring quality to external customers while at the same time paying attention to the needs of internal customers.
\end{abstract}

Aim: assess TQM practices from unit nurse managers' perspectives at Menoufia University hospital.

Design: descriptive research design was used to carry out this study at Menoufia University hospital.

Results: Over half of unit nurse managers perceived TQM practice were at poor level, while below quarter at average level, and more than quarter at good level. Around half of unit nurse managers their perspectives were at poor level for five TQM criteria. Organizational value TQM criteria showed that the highest (44.4\%) poor level was for emergency hospital unit nurse manager. While patient delight TQM criteria showed poor level from unit nurse manager perspective (35\%,50\%, and 55.6\%) for Main University hospital, Oncology institute, Specialty hospital, and Emergency hospital respectively. Process excellence TQM criteria showed that the highest (55.6\%) poor level from unit nurse manager perspective was at Emergency hospital. Organizational learning criteria showed poor level (43.8\%, 50\%, 50\% and 66.7\%) for Specialty hospital, Main University hospital, Oncology institute, and Emergency hospital respectively. Also scorecard excellence criteria showed poor level (31.3\%, $35 \%, 66.7 \%$ and $66.7 \%$ ) for Specialty hospital, Main University hospital, Emergency hospital, and Oncology institute respectively.

Conclusion: Unit nurse managers' perception of TQM practices criteria was poor. As a nurse manager develop, publish and advertise to staff nurses' TQM framework which include value, objective, and quality guidelines. Be role model of TQM culture among staff nurses. Develop clear and effective strategies and supporting plans for achieving TQM objectives.

Keywords: Total Quality management practices; Unit nurse managers' perspectives

\section{Introduction}

Today unit nurse managers face increased job demands as a result of large spans of control that have reduced their visibility and availability to support and mentor nursing staff which led to frustration for both nurses and managers and threatening the quality of their working relationships. Given the importance of this relationship for both nurses' satisfaction and patient care quality, every effort must be made to create satisfying working conditions for managers Laschinger [1].

Nurse supervisor or unit nurse manager has a pivotal role in guiding their staff to work for their patient groups through involving all staff in problem-solving activities, using basic scientific methods and the principles of statistical quality and process control, share management information to foster their commitment, promote professional growth by moving responsibility and control for professional development directly to the staff and technical workers, implement systematic and continued communication among staff members, develop skills in conflict resolution, negotiations, provide education in quality concepts and subjects such as team building, process management, customer service, and leadership Alavi \& Yasin [2]. Unit nursing managers act as a quality model by personally exhibiting desired characteristics and spending time walking around, listening to staff members, learn to be more like a coach, provide autonomy and allow risk taking while being fair and compassionate, engage in the delicate balancing act of ensuring quality to external customers while at the same time paying attention to the needs of internal customers Kamla [3].

The role of the unit nurse manager in developing a quality culture includes major functions that must undertake as vision 
for the institution; a clear commitment to quality improvement, communicate the quality message, meeting customer needs, leading nursing staff development, leading innovation, ensuring that organizational structures have clearly defined responsibilities and provide the maximum delegation compatible with accountability, a commitment to the removal of quality barriers, building effective teams, and developing appropriate mechanisms for monitoring and evaluating success Koh [4]. Nurse supervisor or unit nurse manager is a significant facilitator of quality management and the incorporation of process improvement into day-to-day management functions. The success of TQM program demands that the unit nurse manager be involved by providing leadership to staff nurses and embrace their accountability for quality issues as envisioned in their quality focus Kane [5] Effective unit nurse manager develops and publish corporate beliefs, values and objectives, as a mission statement, personal involvement and acting as role models for a culture of total quality, developing clear and effective strategies and supporting plans for achieving the mission and objectives, reviewing and improving the management system, communicating, motivating and supporting people and encouraging effective staff member participation. Also, nurse manager must take responsibility for preparing, reviewing and monitoring the policy beside take part in regular improvements of it and ensure that staff understand it Zidel [6].

Nurse executives promote continuous improvements in advancing safe, health consumer centered, timely, efficient and cost-effective quality care which is health consumer centered through leadership of the nursing workforce. They achieve this while maximizing the criterion standard measure of success for healthcare organizations, patient health outcomes, such as satisfaction, mortality rates, and hospital admissions Adams [7]. Therefore, this study aims to assess TQM practices from unit nurse managers' perspectives at Menoufia University hospital.

\section{Subjects and Methods}

a. Research Design and Setting: descriptive research design was used to carry out this study at Menoufia University hospital.

b. Subjects: all unit nurse managers (60) at Menoufia University hospitals with at least one year of experience and had bachelor degree in nursing.

c. Sample Size: all unit nurse managers (60) were twenty of them were from the Main University hospital, sixteen from Specialty hospital, eighteen from Emergency hospital, and six from Oncology institute.

d. Tool of Data Collection:

i. $\quad$ Tool (1): Questionnaire sheet to assess TQM practices from unit nurse managers' perspective (Appendix 1), consists of two parts: -

ii. Part One: to collect sociodemographic data from the study sample. It consisted of items related to sociodemographic data of unit nurse managers such as hospital in which they work, qualification, and years of experience.

iii. Part Two: to assess TQM practices from unit nurse managers' perspective, comprised 35 items related to TQM criteria (Organizational value, Patient delight, Process excellence, Organizational learning and Scorecard excellence.

iv. Field of Work: At the beginning it was necessary for the researcher to introduce herself and briefly explain the aim of the study. The questionnaire was distributed to unit nurse managers then the questionnaire collected by the researcher through personal interview. Before distributing the questionnaire, clear instructions were given to each unit nurse manager. The questionnaire sheet was distributed and collected in the same day in front of researcher.

\section{Ethical Considerations}

The study was approved by the ethical committee of the faculty of Nursing, Menoufia University. Written permission was obtained and directed to the administration of the hospital which was selected, then the researcher explained the aim of the study to medical and nursing director to obtain agreement. The study was conducted with careful attention to ethical standards of research and the rights of participants.

\section{Statistical Analysis}

The collected data was organized, tabulated, and statistically analyzed using SPSS version 20 software package. Cronbach alpha coefficient was calculated to assess reliability of the tools through internal consistency. For quantitative data the mean and standard deviation were used. To compare, the significant difference of means and the test ANOVA were used. For qualitative data the number and percent distribution was calculated. Chi square was used as a test of significance. Statistical significance was considered at $\mathrm{p}$-value $<0.05$.

\section{Results}

This study was carried out to assess TQM practices from unit nurse managers perspectives in Menoufia University hospitals. Regarding, socio-demographic characteristics of unit nurse managers. The unit nurse managers $(33.3 \%)$ were working in the Main University hospital. Majority of unit nurse managers (83.3\%) had bachelor degree; also (51.66\%) were in the age group $35-<40$ years with mean age value $38.75 \pm 7.40$. Regarding years of experience (46.8\%) of unit nurse managers had 10- $<14$ years of experience with mean $10.33 \pm 2.87$ years. The majority (95\%) of unit nurse managers were married (Table 1). 
Table 1: Socio-demographic characteristics of unit nurse managers $(n=60)$.

\begin{tabular}{|c|c|c|}
\hline \multirow{2}{*}{ Item } & \multicolumn{2}{|c|}{ Unit nurse managers $n=60$} \\
\hline & No & Percent \% \\
\hline \multicolumn{3}{|l|}{ Hospital } \\
\hline Main university hospital & 20 & $33.3 \%$ \\
\hline Specialty hospital & 16 & $26.7 \%$ \\
\hline Emergency hospital & 18 & $30 \%$ \\
\hline Oncology institute & 6 & $10 \%$ \\
\hline \multicolumn{3}{|l|}{ Education } \\
\hline Bachelor degree & 50 & $83.3 \%$ \\
\hline Nursing diploma after B.Sc. & 7 & $11.7 \%$ \\
\hline MSC & 3 & $5.0 \%$ \\
\hline \multicolumn{3}{|l|}{ Age/year } \\
\hline $30-<35$ years & 25 & $41.66 \%$ \\
\hline $35-<40$ years & 31 & $51.66 \%$ \\
\hline $40-\geq 50$ years & 4 & $6.66 \%$ \\
\hline Mean \pm SD & $38.75 \pm 7.40$ & \\
\hline \multicolumn{3}{|l|}{ Experience } \\
\hline $7-<10$ years & 9 & $15 \%$ \\
\hline $10-<14$ years. & 28 & $46.8 \%$ \\
\hline$\geq 14$ years. & 23 & $38.3 \%$ \\
\hline Mean \pm SD & $10.33 \pm 2.87$ & \\
\hline \multicolumn{3}{|l|}{ Marital status } \\
\hline Single & 2 & $3.33 \%$ \\
\hline Married & 57 & $95 \%$ \\
\hline Widowed & 0 & $0.0 \%$ \\
\hline Divorced & 1 & $1.66 \%$ \\
\hline
\end{tabular}

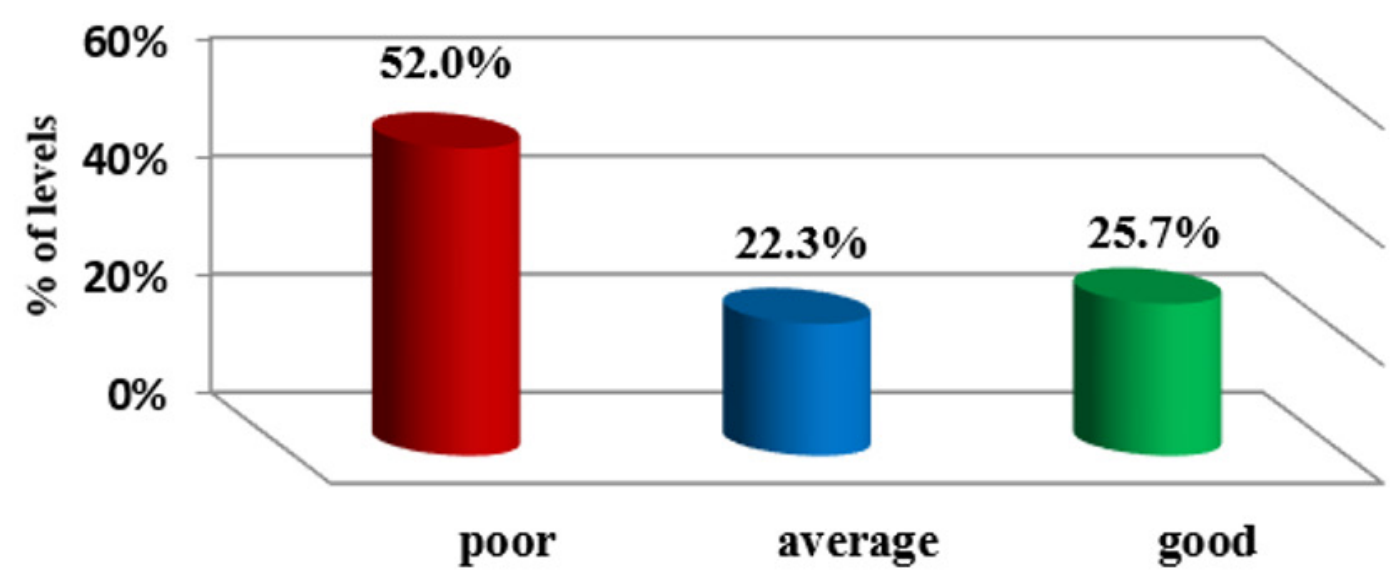

\section{TQM practices}

Figure 1: TQM practices levels from unit nurse Managers' perspectives $(\mathrm{N}=60)$ 
Also, Figure 1. Illustrates TQM practice levels from unit nurse managers' perspectives. Over half of unit nurse managers perceived TQM practice were at poor level, while below quarter at average level, and more than quarter at good level. In addition, around half of unit nurse managers their perspectives were at poor level for five TQM criteria. Around quarter of unit nurse managers their perspectives were at average level for patient delight, organizational learning, scorecard excellence, and process excellence, as well as above third of them for organizational value of TQM practice criteria. Around quarter of their perspectives were at good level for patient delight, scorecard excellence and organizational learning (Figure 2).

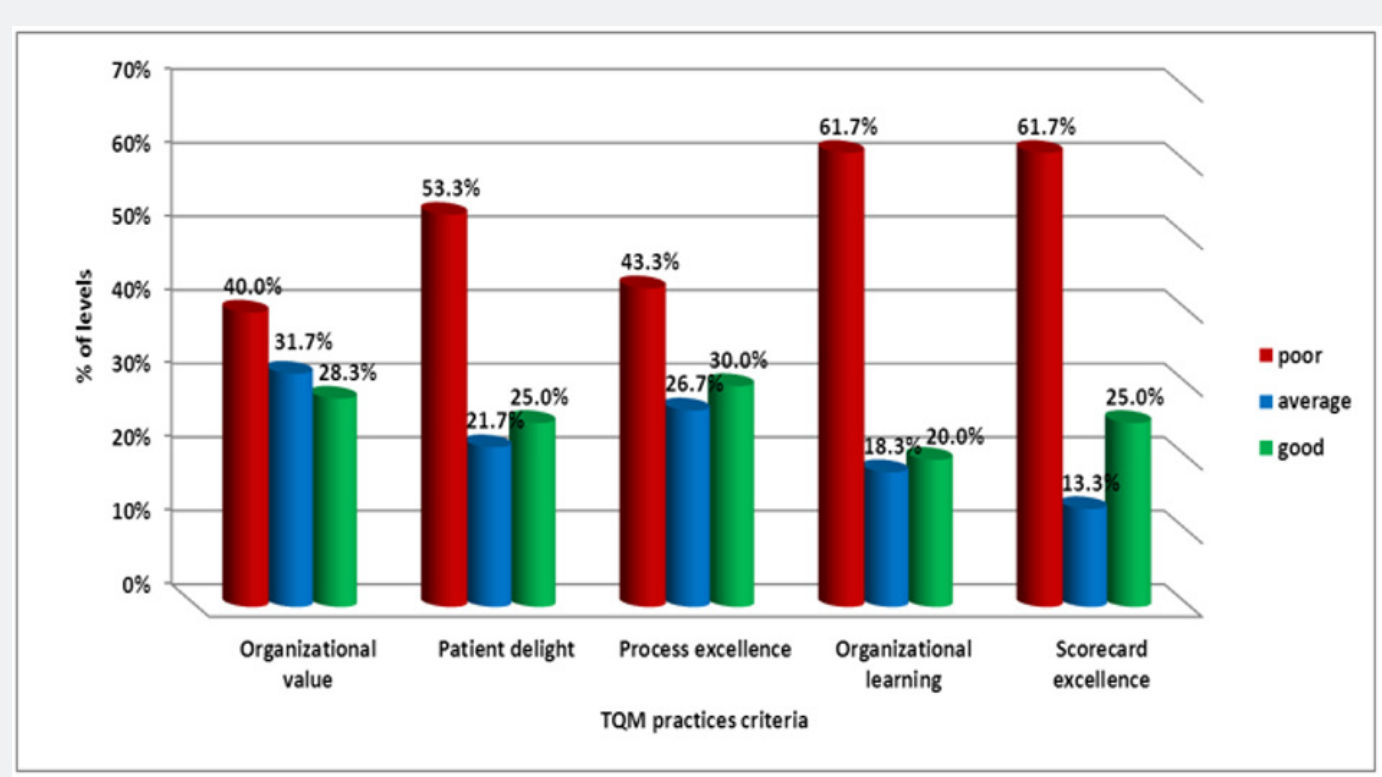

Figure 2: Levels of TQM practice criteria from unit nurse Managers' perspective $(\mathrm{N}=60)$.

Table 2: Differences between four hospitals for each level of TQM practice criteria from unit nurse Managers' perspective.

\begin{tabular}{|c|c|c|c|c|c|c|c|}
\hline \multirow{2}{*}{ TQM criteria } & \multirow{2}{*}{ Level } & \multicolumn{4}{|c|}{ Hospitals } & \multirow{2}{*}{$\mathbf{X}^{2}$} & \multirow{2}{*}{ p-value } \\
\hline & & $\begin{array}{c}\text { Main } \\
\text { university } \\
(\mathrm{n}=20)\end{array}$ & $\begin{array}{c}\text { Specialty } \\
(n=16)\end{array}$ & $\begin{array}{c}\text { Emergency } \\
(n=18)\end{array}$ & $\begin{array}{c}\text { Oncology } \\
\text { institute }(n=6)\end{array}$ & & \\
\hline \multirow{3}{*}{$\begin{array}{l}\text { Organizational } \\
\text { value }\end{array}$} & Poor & $30 \%$ & $25 \%$ & $44.4 \%$ & $33.3 \%$ & 1.7 & 0.94 \\
\hline & Average & $50 \%$ & $50 \%$ & $38.9 \%$ & $50 \%$ & 6.2 & 0.7 \\
\hline & Good & $20 \%$ & $25 \%$ & $16.7 \%$ & $16.7 \%$ & 1.6 & 0.6 \\
\hline \multirow{3}{*}{ Patient delight } & Poor & $35 \%$ & $50 \%$ & $55.6 \%$ & $50 \%$ & 6.2 & 0.39 \\
\hline & Average & $15 \%$ & $6.3 \%$ & $22.2 \%$ & $33.3 \%$ & 1.9 & 0.2 \\
\hline & Good & $50 \%$ & $43.8 \%$ & $22.2 \%$ & $16.7 \%$ & 5.8 & 0.06 \\
\hline \multirow{3}{*}{$\begin{array}{l}\text { Process } \\
\text { excellence }\end{array}$} & Poor & $20 \%$ & $18.8 \%$ & $55.6 \%$ & $33.3 \%$ & 13.8 & $0.03^{*}$ \\
\hline & Average & $50 \%$ & $18.8 \%$ & $22.2 \%$ & $50 \%$ & 9.6 & $0.04^{*}$ \\
\hline & Good & $30 \%$ & $62.5 \%$ & $22.2 \%$ & $16.7 \%$ & 5.4 & $0.03^{*}$ \\
\hline \multirow{3}{*}{$\begin{array}{l}\text { Organizational } \\
\text { learning }\end{array}$} & Poor & $50 \%$ & $43.8 \%$ & $66.7 \%$ & $50 \%$ & 3.3 & 0.77 \\
\hline & Average & $20 \%$ & $18.8 \%$ & $16.7 \%$ & $33.3 \%$ & 1.3 & 0.06 \\
\hline & Good & $30 \%$ & $37.5 \%$ & $16.7 \%$ & $16.7 \%$ & 4.6 & 0.08 \\
\hline \multirow{3}{*}{$\begin{array}{l}\text { Scorecard } \\
\text { excellence }\end{array}$} & Poor & $35 \%$ & $31.3 \%$ & $66.7 \%$ & $66.7 \%$ & 13.3 & $0.04^{*}$ \\
\hline & Average & $35 \%$ & $6.3 \%$ & $11.1 \%$ & $16.7 \%$ & 2.6 & $0.03^{*}$ \\
\hline & Good & $30 \%$ & $62.5 \%$ & $22.2 \%$ & $16.7 \%$ & 7.5 & $0.045^{*}$ \\
\hline
\end{tabular}

*Significant at $P$-value $\leq 0.05$ 
Table 2 shows that there were statistical significant differences at $(\mathrm{P} \leq 0.05)$ among hospitals regarding the three levels of TQM practice criteria for process excellence, organizational learning and scorecard excellence from unit nurse managers' perspective. Organizational value TQM criteria showed that the highest (44.4\%) poor level was for emergency hospital unit nurse manager. Half of unit nurse manager at Main University hospital, Specialty hospital, and Oncology institute showed average level of TQM organizational criteria. While patient delight TQM criteria showed poor level from unit nurse manager perspective (35\%, $50 \%$, and 55.6\%) for Main University hospital, Oncology institute, Specialty hospital and Emergency hospital respectively, also patient delight TQM criteria showed good level from unit nurse manager perspective (43.8\%, and 50\%) for Main University hospital, and Specialty hospital respectively with no statistical significant differences found between four hospitals in the three levels (Table 2).

Process excellence TQM criteria showed that the highest (55.6\%) poor level from unit nurse manager perspective was at Emergency hospital. While it showed average level from half of Main University hospital, and Oncology institute. But process excellence TQM criteria showed highest (62.5\%) good level from perspective of unit nurse manager at specialty hospital. Organizational learning TQM criteria showed poor level from unit nurse manager perspective (43.8\%, 50\%, 50\% and $66.7 \%$ ) for Specialty hospital, Main University hospital, Oncology institute, and Emergency hospital respectively. While scorecard excellence TQM criteria showed poor level from unit nurse manager perspective (31.3\%, 35\%, 66.7\% and 66.7\%) for Specialty hospital, Main University hospital, Emergency hospital, and Oncology institute respectively (Table 2). Also, there was a statistical significant difference among hospitals regarding three levels for organizational value, patient delight, and scorecard excellence criteria of TQM practices at $\mathrm{p} \leq 0.05$.

Organizational value TQM criteria showed good level from staff nurses' perspective (45\%, 48.6\%, 53.3\%, and 58.8\%) for Specialty hospital, Emergency hospital, Oncology institute, and Main University hospital respectively with statistical significant increase in Main University hospital at $\mathrm{p}=0.04$. While patient delight TQM criteria showed good level from staff nurses perspective $(47.5 \%, 51 \%, 60 \%$, and $66.7 \%)$ for Main University hospital, Specialty hospital, Emergency hospital, and Oncology institute respectively with statistical significant increase in Oncology institute at $\mathrm{p}=0.04$. The process excellence TQM criteria showed good level from staff nurses perspective (44\%, 50\%, $54.3 \%$, and $55 \%$ ) for Specialty hospital, Oncology institute, Emergency hospital, and Main University hospital respectively with statistical significant increase at Main University hospital at $\mathrm{p}=0.03$. While organizational learning TQM criteria showed that the highest poor level from staff nurses perspective $(40 \%$ and $42.9 \%$ ) were for Oncology institute and Emergency hospital respectively, and showed the highest average level from staff nurses perspective $(43 \%, 43.3 \%)$ at Specialty hospital, and
Oncology institute respectively. Also, scorecard excellence TQM criteria showed average level from staff nurses perspective $(36.7 \%$, $48 \%$, and $60 \%$ ) for Main University hospital, Specialty hospital, and Oncology institute respectively with statistical significant increase in Oncology institute at $\mathrm{p}=0.02$. And process excellence TQM criteria showed good level from staff nurses perspective (36\%, 36.7\%, 47.5\%, and 48.6\%) for Specialty hospital, Oncology institute, Main University hospital, and Emergency hospital respectively with statistical significant increase in Emergency hospital at $\mathrm{p}=0.01$.

\section{Discussion}

The present research study was concerned to assess total quality management practices from unit nurse managers' perspectives at Menoufia University hospital. Before discussing the results related to this research questions the light should be directed to socio-demographic characteristics of the studied subjects. The result indicate that the majority of unit nurse mangers had bachelor's degree in nursing, at mean age 38.75 and had mean 10.33 years of experience. Really the efficient unit nurse mangers are those having bachelor's degree in nursing being at middle age and had high level of competences from several years of experience related to managerial functions. Mamdouh [8] study about management functions performed by various nursing managerial levels and their perception supported present study results and revealed that most of nurse managers had bachelor degree in nursing with above 10 years of experience.

The present study findings revealed that over half of unit nurse managers their perspectives on TQM was at poor level. The fact is that this result was due to those unit nurse managers' poor perception of organizational value, patient delight, process excellence, organizational learning, and scorecard excellence beside their knowledge about TQM was at poor level. Most probably this result was due to absent of quality department or TQM committee, also no training center at hospitals under study for guiding, developing and training of nurse managers on TQM activities. Beside unit nurse managers were not encouraged to take more responsibilities or act creatively in managing their units. Hospital and healthcare system training and development center becomes increasingly important. Such center can improve nurses' skills and positively impact the overall quality of health system. Training and development of initiatives are important for health system leaders, specially that they are faced with pressing issue such as reimbursement, compliance, and clinical quality. Educational training centers in hospitals is required to combine and design training for each nurse category to serve their multiple responsibilities. Hospital should also assess the effectiveness of their training programs through surveys and testing skills Lindesy [9], Emad [10] suggested that poor implementation of TQM may be attributed to deficient knowledge about the importance of TQM and insufficient training programs and poor financial support for improving health services and patient satisfaction. Also, Sutherasan and Aungsuroch [11] stated that poor TQM implementation in healthcare organizations were caused by lack 
of senior management commitment, unclear mission statements, the short-term orientation of administrators, poor communication of the strategies and goals of the organization, tensions and misunderstanding between management and medical professionals, resistance to change by physicians, nurses and other medical staff. Gunjan [12] study TQM in healthcare Manipal University and revealed that TQM movements were not concerns about quality in healthcare. While Preto (2009) study about TQM model to improve patient satisfaction, not support present study result but noted that total quality management is successful in nursing, encompassing the role of leadership, planning actions based on indicators and standardized instruments, improving cost-benefit, education and training, clients' satisfaction, encouraging people's development and valorization, and focusing on communication processes among others.

Analysis of findings of the present study revealed that unit nurse managers had poor level of perception on organizational value criteria. Most probably this poor perception of unit nurse managers about quality of organizational value was because their higher-level leaders and top management assume poor responsibility for quality performance and not act as quality models. Beside those unit nurse managers have poor opportunities for promotion, growth and support. Also, the poor value of organization system to satisfy staff nurses' work and personal needs. Adding to the poor invests on the improvement of information and performance measurements. However, Grossman and Valiga [13] study about the new leadership challenge creating the future of nursing, stated that creating a shared vision for a mentoring culture was an essential element in creating mentoring cultures and stressed the importance of nurse leaders inspiring a shared vision and enlisting others in the process.

Also, Spurgeon and Cragg [14] indicated that effective managers inspired and mobilized others to become involved in creating a shared vision and working towards a goal that was meaningful to them. Tova [15] study about maximizing innovation in healthcare using TQM, support present study and revealed that head nurses did not yet fully internalize the new organizational values. In the same line Emad [10] stated that full and complete value of TQM might not yet be fully appreciated and concluded that the extent of implementing TQM in the Jordanian hospitals was very poor. While Pamela (2011) study about quality health outcomes model, not support present study result but stated that nurse managers straddle the worlds of staff and middle- upper management, ensuring a two-way flow of communication. They translate and promote organizational goals to frontline staff and remove barriers that could hinder their performance, also keep pace with current advances in care and technology as well as regulatory and legal requirements. Zhihai [16] concluded that it is imperative that nursing management fosters the participation of the nursing staff in quality improvement and develops a quality culture by changing perception and attitudes towards quality. The importance of education and training is emphasized in changing nursing staff' beliefs, behavior and attitudes and enhancing their competencies in carrying out their duties. There is a broad agreement that all aspects of activities should be looked at for quality improvement. Functional integration is an important ingredient of TQM.

The findings of the present study revealed that more than half of unit nurse managers' perception of patient delight criteria was at poor level. The fact is that those unit nurse managers perceived that their hospitals were poorly or not established mechanism to understand, measure or to support patients' needs and expectations. Therefore, the care practices and procedures were not focused on delivering patient satisfaction or provide training on patient awareness and services. Also handling complaints, resolving them and using feedback to improve service delivery were at average level of efficiency. As well as their poor link of patient as recognition and appreciation to the system for patient satisfaction. Emad [10] supported the present study result and explained that $70 \%$ of variance in implementing TQM can be achieved by the principles of TQM which are continuous improvement, teamwork, training, top management commitment and customer focus. But TQM was implemented in Jordanian hospitals at a level approximately less than $60 \%$. The most implemented principle was customer focus and the least implemented was continuous improvement. It was revealed that the private sector implemented these five principles more than other sectors. Boadu [17] study about an assessment of consumer care and staff action and satisfaction in government healthcare institution in Ghana, not support the present study result but revealed that hospital is more consumer-focused and market-oriented this time than before due to the emerging competition in the healthcare industry in the municipality and added that the hospital has the capacity to improve its consumer care and satisfactions. Crystal [18] study about developing and implementing quality program in the health care organizations, explained that when an effective quality improvement program is in place there is increased efficiency throughout data collection and measurement. Often hospitals will benchmark against similar hospital or sometimes hospitals will benchmark against a top performing hospital.

Findings of present study revealed that unit nurse managers' perception of process excellence criteria was at poor or average level. Most probably those unit nurse managers' poor perception about quality of process excellence were because the interdependent tasks are poorly coordinated to meet high quality standard. Beside the poor use of the methods for regularly assessing staff expectation and satisfaction. Adding to the poor use of indicators and measurements to improve the services provided and the management of the institution. John [19] study about evaluating the quality of healthcare facilities, support the presence of bad quality of clinical leaders at all levels of the organization, not fostering organizational cultures thus not support nursing leadership development and staff retention. While, a quality 
nursing leadership team and an empowered and satisfied nursing staff could be the key to enhancing the quality of patient care and the image of the nursing profession. Gunjan [12] explained that achieving quality and healthcare service leadership requires a strong future orientation and a willingness to make long-term relations to key customers, employees, doctors, nurses, suppliers, the public and private community. Through their personal roles in planning, reviewing healthcare quality performance, and staffs for quality achieving, the senior's leaders serve as role model reinforcing the values and encouraging leadership through the organization. However, Pamela [20] not support the present study result but revealed that nurse manager encourages and monitors performance of staff nurses at the unit or department level and evaluate results that build across the organization. Also, Mohamed [21] not support the study result but concluded that the role of the head of management is to create and maintain the culture of team work and cooperation with the objective of quality improvement. Their study was evaluated as a great improvement in having a teamwork atmosphere in hospital system which was suggested strongly to other wards of the hospital, as well as health care organizations in the country.

Also, the present study revealed that unit nurse managers' perception of organizational learning criteria was at poor level. The reality that those unit nurse managers were poorly equipped with specialist knowledge and experience to successfully perform their jobs. Beside quality related training not given to all healthcare professionals and administrative staff members. While people and teams that make significant contributions to quality improvement were ineffectively rewarded. Adding to that the staff nurses were poorly collaborating to provide quality services. While Balghonaim [22] study on quality improvement in health care stressed that the implementation of TQM involves everything and everyone in the organization from top management to first line management from the input to the output. Team work is very important when implementing TQM so that the goal can be reached effectively and efficiently. Ihab [23] study about application of kano methods and quality function deployment to the design of quality improvement training programs in healthcare organizations, support the study result and approved that effective TQM training and education could be considered a critical factor in the success of TQM efforts in healthcare organizations. Also, Boyle [24] assure that training is a key component in the implementation of TQM programs in many venues and particularly in healthcare. Weston [25] study about reaping benefits from intellectual capital, support the study result and illustrated that the significance of infrastructure in the hospital environment in promoting and infusing best practices and for maximizing the intellectual capital of nurses by creating learning environments. Linda [26] study about nurse managers, support study result and stated that the nurse manager must create a learning environment that is open and respectful and facilitate the sharing of expertise to promote quality care. The ability of nurse managers to enhance the practice environment is critical to the recruitment and retention of registered nurses with diverse backgrounds and appropriate education and experience. Noelle [27] added that nurse managers required the support and engagement of senior nursing executives in hospital organizations to be successful in creating mentoring cultures on their units. Emad [10] not support the study result and pointed that training and top managerial commitments were applied at Irbid Specialty hospital than at the University hospital and the government hospital. All other hospitals applied TQM similarly, except for top management commitment which was applied more in the military hospital compared to the government hospital.

Results revealed that unit nurse managers' perception of scorecard excellence criteria was at poorlevel. This poor perception caused by the situation of human resource management system that poorly support its quality policy. Beside the ineffective policies for recruiting and maintaining excellent health care professionals and other staff. Adding to the poor employee performance appraisal system. Also, the staff members are poorly encouraged to contribute effectively to quality improvement and work as a team. As well as the hospital poorly facilitate open communication across the organizational levels and departments. Beata [28] study about performance measurement systems in Swedish healthcare services, support present study result and said that it is important for health care managers to reflect on and identify the need to develop a performance measurement system and hence enable the development process. Also, the goal to develop the performance measurement system need to be clearly identified and communicated in the organization. There is need to understand and accept that the development process is characterized by many and unpredictable events which is most probably the responsibility and important experience for health care managers.

\section{Conclusion}

Develop, publish and advertise to staff nurses' TQM framework which include value, objective, and quality guidelines, Be role model of TQM culture among staff nurses, Develop clear and effective strategies and supporting plans for achieving TQM objectives, Reviewing and be familiar with process, methods and policies to improve unit structure, operations and outcome, Motivating and coaching staff nurses and employees in her unit to define and achieve objectives of TQM, Provide leadership to unit staff nurses and equip them with the needed tools to perform TQM knowledge, Establish TQM committee to control, direct and make resources allocation for the unit, Periodically analyze the unit activities and solve its problems.

\section{References}

1. Laschinger H, Wong C (2007) A profile of the structure and impact of nursing management in Canadian hospitals. Ottawa ON: Canadian Health Services Research Foundation.

2. Alavi J, Yasin M (2008) Total Quality Management (TQM) Factors: The role of quality improvement initiatives in healthcare operational environments. International. Journal of Health Care Quality Assurance 21(2): 133-145. 
3. Kamla R (2011) Total Quality Management (TQM) Factors: An Empirical Study of Kwara State Government Hospitals. Business Administration Department, University of Ilorin, Ilorin. Nigeria. Ethno Med 5(1): 17-23.

4. Koh T (2008) Organizational culture and TQM implementation in Singapore. Construction Management 26(3): 237-248.

5. Kane L (2007) The association of registered nurse staffing levels and patient outcomes. Medical Care 45(3): 195-204.

6. Zidel T (2007) A Lean guide to transforming healthcare: How to implement lean principles in hospitals, medical offices, clinics, and other healthcare organizations. Milwaukee: ASQ Press, Wisconsin.

7. Adams J, Erickson J, Jones D, Paulo L (2009) An evidence based structure for transformative nurse executive practice. Nursing Administration Quarterly 33(4): 280-287.

8. Mamdouh M (2011) Management functions performed by various nursing managerial levels and their perception. Master thesis, Faculty of nursing, Mnoufia University, Egypt, p. 45.

9. Lindesy D (2012) Best practices for hospital training and development programs.

10. Emad A (2015) Implementation of Total Quality Management in hospitals. PhD College of Nursing, University of Dammam, Dammam, KSA Taibah University. Journal of Taibah University Medical Sciences 10(3): 1-6.

11. Sutherasan S, Aungsuroch Y (2008) Total quality management activities after hospital accreditation from the opinion of hospital accreditation coordinators in Thailand. Thailand Songkla Med J 26(4): 313-321.

12. Gunjan P (2009) Total Quality Management in Healthcare. Manipal University p. 1-4

13. Grossman S, Valiga T (2009) The new leadership challenge: Creating the future of nursing. ( $3^{\text {rd }}$ edn) Davis company, Philadelphia, pp. 213.

14. Spurgeon P, Cragg R (2007) Is it management or leadership? Clinician in Management 15(3/4): 123-125.

15. Tova $P$ (2014) Maximizing innovation in healthcare using total quality management. Medical Care Issue; 32(2): 57-66.
16. Zhihai Z (2010) Developing Quality Management Method Model. JONA 3. 53

17. Boadu F (2011) An assessment of consumer care and staff action and satisfaction in government healthcare institution in Ghana. Master Thesis of Distance Learning, Kwame Nkrumah University of Science and Technology, p. 54-56.

18. Crystal L (2008) Developing and implementing quality programs in the health care organizations. JONA 37(5): 55-56.

19. John M (2006) Evaluating the quality of healthcare facilities: Development of an assessment tool. Journal of Administration 22(13): 8-9.

20. Pamela M (2011) Quality Health Outcomes Model. Journal of Nursing Scholarship.

21. Mohammad H, Saeed A, Ali M, Ali R (2015) Effects of the Total Quality Management Implication on Patient Satisfaction in the Emergency Department of Military Hospitals. AJA University of Medical Sciences, Tehran, Iran J Arch Mil Med 3(1): 1-5.

22. Balghonaim T (2010) Quality Improvement in Health Care. New England Journal of Medicine 140(1): 118-122.

23. Ihab A (2013) Application of kano methods and quality function deployment to the design of quality improvement training programs in healthcare organizations. Master Thesis, Faculty of California State University Dominguez Hills, p. 3-5 \& 68-70.

24. Boyle J, Martin D, Gerik C (2012) Implementation of TQM in healthcare Journal of quality management 17(3): 235-238.

25. Weston MJ, Estrada NA, Carrington J (2007) Reaping benefits from intellectual capital. Nursing Administration Quarterly 31(1): 6-12.

26. Linda K (2010) Nurse manager Doctoral Philosophy degree in Nursing College of the university of Iowa, Iowa, pp.112-126.

27. Noelle K (2012) Committing to Mentorship: Nurse Managers Perceptions of their Roles in Creating Mentoring Cultures. Doctoral Thesis. College of Nursing, University of Saskatchewan, Saskatoon Saskatchewan 8: 71-73.

28. Beata K (2007) Performance Measurement Systems in Swedish Health Care Services. Quality Technology and Management. Linköpings university, Sweden, p. 61-67.

\section{Your next submission with Juniper Publishers will reach you the below assets}

- Quality Editorial service

- Swift Peer Review

- Reprints availability

- E-prints Service

- Manuscript Podcast for convenient understanding

- Global attainment for your research

- Manuscript accessibility in different formats

(Pdf, E-pub, Full Text, Audio)

- Unceasing customer service

Track the below URL for one-step submission https://juniperpublishers.com/online-submission.php 